\title{
Future Prospects on Coping with Nuclear Waste
}

\author{
Gordon MacKerron'
}

\section{Abstract}

Finding safe and publicly acceptable routes for the management of long-lived nuclear wastes has been problematic in all countries that have used nuclear power. The dominant expectation on the part of Governments and the nuclear industry has been that the best option will be deep underground disposal. However even in Sweden, where political consensus has emerged over a site for a repository, disputes continue about long-term safety. Ethical issues, especially inter-generational equity, are relevant given continuing delays in implementing long-term management and where countries, like the UK, continue to build new reactors, achieving political acceptability is more problematic than where new-build is not an option. Failure to resolve nuclear waste issues is a major obstacle to public acceptance of nuclear technology.

1 Gordon MacKerron, University of Sussex, United Kingdom, gordon@mackerron.co.uk

(C) The Author(s) 2019

R. Haas et al. (Eds.), The Technological and Economic Future of Nuclear Power, Energiepolitik und Klimaschutz. Energy Policy 


\section{Introduction}

Radioactive waste is for many people the single most problematic issue surrounding nuclear power. For the great majority of countries using nuclear power, there has been little or no progress in resolving the waste issue. This chapter provides an overview of the main issues, with illustrations from a range of countries.

Generation of nuclear electricity produces radioactive substances, some not found in nature that are extremely hazardous. In many cases they remain potentially harmful to human health and the environment for thousands of years. Although there is now a history of nuclear generation stretching back 60 years - and a military legacy that goes back further - there is, as yet, no long-term management facility for the most problematic civilian wastes completed anywhere in the world.

This is not for want of trying. Most nuclear-using countries have official policies that endorse the option of deep geological disposal (DGD) as the favoured strategy for trying to isolate wastes from the biosphere for very long periods in the future. But few countries have made any significant progress towards building such a repository (Finland and Sweden (Swahn and Kaberger 2015) are rare, if still partial, exceptions). The failure to establish long-term management routes is a predominantly social and political question and can generally be attributed to a lack of trust on the part of affected populations, locally and nationally, in the technical solutions that have been proposed, reflecting in turn a poor history of nuclear waste governance.

\section{The wastes}

Radioactive wastes arise at several points in the nuclear cycle but the main problem is about so-called 'higher activity' wastes. These have the characteristics that they are highly radioactive and remain hazardous for long periods in to the future generally measured in centuries or longer.

These higher activity wastes are of two main types. The first are 'high level' wastes (HLW), which besides being highly radioactive and long-lasting are also heat generating and so need periods of cooling before they can be managed effectively [(MacKerron 2015). These wastes are almost entirely the product of fission in reactors and consist either of spent fuel, or some of the separated components of spent fuel, including plutonium. Separation of plutonium and unburned uranium from spent fuel is known as 'reprocessing'. This is a complex chemical and mechanical process that creates new waste streams and is now undertaken by few countries (including the UK, France and Russia, with Japan expected to open its 
long-delayed reprocessing plant sometime soon (World Nuclear News 2017)). Plutonium is sometimes combined with uranium to make so-called mixed-oxide fuel (MOX) and then used in current commercial reactors. This however only postpones the waste issue. The reason is that it is impractical to reprocess MOX fuel, which is radioactively hotter and more difficult to manage than conventional spent fuel (von Hippel and MacKerron2015).

However, much of the world's civilian separated plutonium is currently stored (especially in the UK and France), pending decisions on whether to treat it as waste or first make it into MOX. The rationale for plutonium separation was originally found in the nuclear weapons' states desire to produce fissile material for bombs (Gowing 1974). Later a new rationale developed. This derived from the intention of several countries from the 1950s onwards to develop 'fast breeder' reactors, which would depend on large quantities of plutonium as a start-up fuel, after which reactors would generate their own fuel. Fast reactors have now been abandoned by most of their original supporting countries (the USA, the UK, France and Germany) though ambitions for fast reactors persist in Russia, India, and China (Cochran et al. 2010).

The second waste category consists of 'intermediate level' wastes (ILW) which are also radioactive and long-lasting but not heat-generating. Most countries expect to manage HLW and ILW (especially the longest-lasting ILW) together in a deep repository (OECD/NEA 2013 chapters 1 and 2). ILW arises from a number of sources, including reactor operation and - where reprocessing of spent fuel takes place - some of the waste streams that reprocessing creates. Other wastes, mostly low level (LLW) are less radioactive and are dangerous for shorter time periods. Such wastes are in most cases already managed with little controversy, often in shallow burial sites. The rest of this chapter concentrates on the higher activity wastes.

\section{Proposed technological solutions}

For several decades the overwhelmingly dominant expectation on the part of Governments and the nuclear industry has been that higher activity wastes will at some point be subject to buried in a deep geological disposal (DGD). This would be some distance underground - at least 500 metres or more - and would rely both on the host rock as well as engineered safety to contain the wastes safely for what is hoped to be more or less indefinite periods in to the future. While other routes for long-term management of wastes have been seriously considered - for example sub-seabed disposal, shooting wastes into space or beneath ice caps - all have 
fallen by the wayside in recent years in the face of perceived risks, international law obstacles or excessive cost (CoRWM 2006, Chapter 10).

Several different geologies appear in principle suitable as host environments for a DGD repository. This has included granites (Scandinavia), salt (Germany) and clay (France). (Brunnengraber et al. 2015, Part 1) While the geology is expected to form part of the barrier to the escape of radioactivity, all DGD proposals also expect that there will be multiple engineered barriers. Wastes will be sealed in canisters or drums which themselves contain internal barriers and then further materials, for example bentonite clay, may be used to provide a further barrier between the waste-containing structure and the host rock.

One variant of the DGD idea is the potential use of boreholes for the disposal of particularly difficult wastes, such as immobilized plutonium (Gibb et al. 2008). Such boreholes might be at a depth of $3-5$ kilometers, where geological formations are in principle especially stable. If such a method became feasible - and at present there are concerns about the reliability of drilling technology to such depths - the relatively small diameter of boreholes suggests that such an option would probably only work for quite small waste volumes.

While the great bulk of opinion favours a DGD route for long-term management of higher activity wastes, there are sharp divisions between those who want a repository closed and sealed as soon as all relevant waste is emplaced, and those who favour retrievability or reversibility for some substantial future period (CoRWM 2006, Chapter 10). The argument in support of prompt closure is that the safety and security cases are stronger if a repository is closed and sealed as soon as possible. In practice such 'early' closure will probably be at least 100 years in the future for major nuclear-using countries and there are concerns that leaving a repository accessible for longer is risky, given the difficulty of knowing how societies will evolve centuries into the future.

The opposing argument - in favour of retrievability - is that maintaining access to waste, proposed in the UK case for up to 300 years (MacKerron 2015), allows for flexibility if circumstances change. There are two possible changes in circumstances envisaged in this argument. The first is that is that new technology might allow the period over which waste is hazardous to be radically reduced. Such ideas already have some currency in the notion that so-called partitioning and transmutation (P\&T) might drastically reduce the half-lives of several isotopes (Schneider and Marignac 2008). However P\&T would be extremely expensive and in any case could not reduce half-lives of some of the isotopes with longest lives. The second possible change is that it might be possible to recover the waste and use it as fuel for new kinds of nuclear technology. This also has current advocates but runs into the problem that further wastes will be created (OECD/NEA 2013 Chapter 4). 


\section{$4 \quad$ Issues of repository design and long-term safety}

Beneath this widespread generic endorsement of DGD there are many technical arguments about specific repository design. For example in Sweden the confidence that was once widely shared about the so-called KBS design - which has provided a starting point for other countries' efforts, including Finland and the UK - has been eroded in recent years by concerns that the corrosion-resistance of the copper that is integral to the design might be compromised. Equally there have been long-running disputes in the US scientific community about the long-term safety of the design proposed for the (now abandoned) Yucca mountain site in Nevada (Macfarlane and Ewing 2006).

While no country has expressed the view that an alternative to DGD is a good long-term way forward, some have deliberately postponed any long-term decision. The Netherlands for example has a policy of storing wastes for around 100 years before expecting to make a long-term decision (Arentsen 2015). A few countries, for example Italy and Spain, have been influenced by this approach, but no-one seriously argues that continuing storage is an acceptable long-term way forward. This raises questions of equity between generations that are explored further below. Virtually all other nuclear-using countries are committed to a search for a way to move DGD forward as quickly - in practice generally very slowly - as possible.

In this process of trying to find a way to implement DGD the almost universal assumption has been that every country needs to take responsibility for managing its domestically generated wastes within its own borders. There have been a few exceptions to this. Russia used to take back spent fuel from the reactors it sold to its East European client states, and very small quantities of waste have been transferred between countries (for example between Georgia and the UK) (Abbott 1998). But the principle that wastes should be the responsibility of the states that generate them is still the norm.

Nevertheless proposals periodically surface to develop multi-national disposal sites - for example within Europe and more improbably in Western Australia. While these have superficial attractions, such as possible cost savings and the remoteness of some of the potential sites, thy have all floundered on mixed political and ethical grounds - the unacceptability that some countries will take on burdens that should belong elsewhere. For all practical purposes the issue of waste disposal is one that needs to be solved within each individual nuclear-waste-producing country.

Despite the near-consensus on the desirability of a DGD approach to waste management, the very limited progress to date on implementing such projects is striking. Only Finland and Sweden have made serious progress in this area. In the case of Sweden it is noteworthy that there has been serious engagement with local 
candidate communities - both of which were very close to pre-existing nuclear sites - and they were given the option of withdrawal if the terms offered were regarded as unacceptable (CoRWM 2006, Chapter 9). In Finland, with a tradition of consensual decision-making, there has been community consent for the construction of a repository and the process of first building an underground laboratory has been ongoing since 2011 (Auffermann et al. 2015). Construction of a full-scale repository has started and it is possible that an operating licence may be granted by 2020 . Sweden has also gone through a process of canvassing communities for volunteers and two sites proved willing to act as hosts, with one now selected (Swahn and Kaberger 2015). Even in these countries, the process of emplacing wastes will take many decades, and for other countries the timescale will be substantially longer.

In all other countries progress has been much more limited. In France a candidate site - Bure, in a thinly populated part of eastern France - has been selected in a much more top-down process, but it is not clear when (or of) construction will begin (Blowers 2017, chapter 4). Elsewhere there is even less progress. In the USA, there has been a protracted process in which Yucca Mountain was selected as the preferred site for DGD, but there were a long series of legal challenges and much public and local political resistance over many years which led to the site being effectively abandoned in 2011 (Macfarlane and Ewing 2006). In Germany, where there have long been proposals for three sites for different waste categories, there have been apparently intractable delays, and a fierce anti-nuclear movement, as well as local citizen movements, that have meant that there has been no progress towards a solution for many years (Hocke and Kallenbach-Herbert 2015). In Canada a stepwise process through its NWMO, involving wide-ranging engagement has led to the potential choice of a site in Ontario but recent progress has been slow, with no agreement yet reached (NWMO 2018).

In the UK a new process was initiated in 2003 with the formation of the Committee on Radioactive Waste Management (CoRWM) charged with formulating a new approach to policy. CoRWM reported in 2006, broadly endorsing a DGD end-point and recommending that only a voluntarist approach would work (CoRWM 2006, Chapter 14)]. This was endorsed by the UK Government (Defra, BERR and the devolved administrations for Wales and Northern Ireland 2008) and after local authorities in the area around the Sellafield nuclear site provisionally volunteered there followed a three year period of intense negotiation. However this was brought to a halt in 2012, when Cumbria County Council refused permission to take negotiations any further. This means that the UK, in common with many other countries, still has no agreed site for a repository. 


\section{$5 \quad$ Ethics}

The objective of implementing long-term management options for higher activity wastes raises important issues in ethics - specifically, equity both within and across generations. Intra-generational equity issues surround the location of waste management sites, where local communities assume the burden of responsibility while distant communities are exempted. This strongly suggests recompense for the community willing to take on a national burden.

Inter-generational equity is more problematic. The benefits of nuclear power in terms of power production have been experienced in the present and past. But in the absence, as seen above, of any satisfactory waste management solution in most countries, the costs and risks associated with nuclear waste will affect future generations, who will experience no compensating advantages (CoRWM 2006, Chapter 6) In terms of environmental principles this is a clear case of violating the 'polluter pays' principle. Attempts to avoid this violation by ensuring that funding is put aside now to cover future costs are not credible. The existence of such funds may mean that future generations have a prior claim on resources to manage waste, but the real resources needed - labour and capital equipment - fall to future generations to find and are at the expense of other potential uses of those resources in the future as well as representing risks to workers and possibly others.

On ethical grounds it is therefore important to try and find a way to manage wastes in a safe and secure way as soon as practically possible because the interests of all generations are at stake. If above-ground storage is more hazardous in the next few decades than burying waste, then the interests of this generation as well as future generations are that burial should be achieved as soon as practical. The argument for early action is therefore strong provided there is confidence that early commitment to a repository does not jeopardize the safety of future generations (CoRWM 2006, Chapter 13). But as argued above, the universal expectation is that even in countries where waste management plans are far advanced, the process of completing the burial of wastes will take up to a century or more. So even an effective waste management programme will cause some burdens to be passed to future generations and possibly expose current generations to significant risks in the meantime. 


\section{The politics of nuclear waste}

Given the scientific consensus, established over decades, that a DGD route is potentially achievable and can in principle be made safe over many future generations, the extreme slowness in the process of implementation needs explanation. The most commonly observed reason for this universal failure is a chronic lack of public trust in the process of nuclear waste governance, and that this lack has made progress at potentially favoured DGD sites impossible - or at best exceptionally slow.

The question behind this observed lack of trust is why it should be so. Until around 2000, decision-making processes for nuclear waste management were almost universally centralized, opaque, used narrowly scientific criteria, and failed to engage with either local communities or publics. This was, especially for nuclear weapons states, partly a legacy of the secret and closed nature of all decisions about nuclear technology. Characteristically, the process was that a small elite group of government officials, nuclear industry leaders and scientists would endorse the idea of geological disposal and then announce a chosen site for a repository. This would be followed by highly vocal, local campaigns against the choice of the site, often involving coalitions of actors of quite different general political views, sometimes national and even international. Abandonment of the proposed site followed (the UK) or there would be delays lasting decades and becoming indefinite (USA and Germany)

This became known as the 'decide-announce-defend' style of decision-making (CoRWM 2006, Chapter 1), to which could then be added 'abandon' (DADA) when local communities and their wider supporters resisted. This exacerbated and to a degree helped create the lack of trust on the part of many citizens towards decision-makers in Government and the nuclear industry.

Around the turn of the century a combination of repeated failures to establish a DGD site and a new more participatory approach to decision-making in several countries - an approach which was applied to other 'difficult' areas of decision involving controversy, such as GM food - led several countries to introduce a more deliberative and open style of decision-making (Chilvers and Burgess 2008). This so-called 'deliberative turn' in decision-making processes has had some positive results. Where such processes have led to some real progress, as in Sweden, there seem to have been two conditions, one pre-existing and the other specific to waste management. The first condition seems to have been relatively high levels of initial public trust in relevant institutions including the nuclear industry. The second, strongly exemplified in Sweden, was a process of deep engagement with communities that first volunteered as repository sites, but were also given the op- 
portunity to withdraw from the process if they found the proposals being offered were unattractive (CoRWM 2006, Chapter 9)

Countries like Canada and the UK also followed more participatory and deliberative models in trying to formulate more effective waste policies in the $2000 \mathrm{~s}$. In the UK, CoRWM was given a 'blank sheet of paper', with emphasis in its terms of reference to consult widely and to 'inspire public confidence' (CoRWM 2006, Annex 1), a commodity previously in short supply. CoRWM took a consciously 'analytic-deliberative' approach to its work and conducted very wide-ranging engagements with both stakeholders and non-aligned members of the public. Its 2006 report endorsed DGD as the desirable end-point but its most important recommendation $[c]$, endorsed subsequently by Government (Defra, BERR and the devolved administrations for Wales and Northern Ireland 2008), was that communities should be invited to volunteer to become potential repository sites, to be resourced to do this effectively, and to be given a right to withdraw participation if the terms being offered were unattractive.

This new approach did improve the level of trust in the policy process but was no guarantee of success. As outlined below the ongoing revival of Government commitment to new nuclear power (HMG 2017) has made it more difficult to achieve agreement on a way forward for higher activity wastes.

While the widespread move towards more participatory forms of decision-making has improved trust and made progress more likely, it has not been a panacea. Even in its own terms it has had problems in rectifying the power imbalances that inevitably exist between local communities and the combined forces on the State and the nuclear power industry. A critique of the CoRWM process suggests that while its greater openness and engagement were helpful, it was still subject to important framing processes within which the influence of powerful incumbent actors could not be countered (Chilvers and Burgess 2008).

The politics of nuclear waste also extend well beyond the issue of local siting. Local opposition to siting proposals have often been influenced and bolstered by national and international forces. Environmental NGOs like Greenpeace have often majored on the waste (and associated reprocessing) issues and in countries like Germany a wide range of political forces - not all of them associated with environmentalism - have joined together to resist proposals for waste management solutions at national level.

This wider than purely local current of resistance to the policy of burying waste has at least two strands. One is the idea that it is impossible to demonstrate that any underground repository can guarantee that there will be no return of radioactivity to the biosphere for hundreds of thousands of years. And while most scientists in this field argue that it may be possible to make a DGD adequately safe this often falls 
short of endorsing a particular site, and/or the precise methods proposed to try and contain the waste within the repository. And of course no-one can guarantee the integrity of a repository thousands of years in the future (CoRWM 2006, Chapter 13)

A second strand concerns the meaning of emplacing waste deep underground. The colloquial version of this argument is 'out of sight, out of mind' involving a suspicion that the purpose of deep disposal is to make invisible the problem that the waste was created in the first place. This argument is used by those who have more wide-ranging objections to nuclear power, but is also visible among others who do not hold such views. It is often associated with scepticism about the robustness of the safety case that can be made for DGD and has been particularly strong where reprocessing of spent fuel has added complexity to the management task.

The politics (and ethics) of waste management can also vary sharply depending on the status of nuclear power within a country. Where a decision is made to abandon nuclear power the waste issue becomes purely one of managing a legacy. If there is trust that the decision to abandon nuclear power is final, then the issue becomes simply one of finding the 'least worst' way of managing the waste legacy (CoRWM 2006, Chapter 14). In such situations it has sometimes proved possible to bring together people of varying opinions about nuclear power - supporters and opponents - in the common cause of finding a solution. This was the case in 2003 in the UK when, on the formation of CoRWM in 2003, it appeared that there would be no future role for nuclear power in the UK (DTI 2003).

The problem can become more intractable when there is an ongoing programme of building new nuclear power. The politics and ethics here are different. The question is no longer how to find the least worst way to manage waste but rather whether proceeding with nuclear power is justifiable, given that more waste will ensue, and that there are alternative paths for power production that do not impose the same potential burdens on future generations. At local level this translates into uncertainty for a community in terms of how much waste they may eventually need to receive, and is likely therefore to lead to greater resistance than if it knows it will host a fixed legacy. Where such commitments to new nuclear construction are strong, as in the UK, resistance to an 'out of sight out of mind' solution to waste management has become stronger - due to a conviction that getting the waste out of the way is being used simply as a legitimation device for the advance of new nuclear construction. The stance of the UK Government on this - that it has confidence that a long-term management route for waste 'will' exist (Defra BERR and the devolved administrations for Wales and Northern Ireland 2008)- has had the tendency to reduce public trust, especially as it was as long ago as 1976 that an influential report advocated that there should be no going ahead with a substantial nuclear programme unless it 
could be demonstrated that a route existed (Royal Commission on Environmental Pollution1976) (not 'will exist') to manage waste effectively.

\section{Conclusions}

Failure across all nuclear-using countries to implement technically convincing and publicly acceptable ways of dealing with higher activity wastes has been a feature of nuclear power across the world for several decades. There have been some small advances since the Fukushima accident in a few countries, primarily Finland and Sweden, but even in those cases, no operating repository will open until 2020 at best. Further, there seem to be distinct features of Nordic political systems, especially higher degrees of public trust and consensual decision-making styles that are hard to replicate elsewhere. While issues like safety, security and proliferation risk remain problematic, it is the inability of all countries yet to find a credible long-term way forward to manage the most dangerous categories of waste that is the primary stumbling bock to acceptance of the technology.

\section{References}

Abbott, A., 1998. 'UK waives nuclear waste rule for Georgia' Nature 392: 850 (30 April 1998). Arentsen, M.J., 2015. 'With access to the future. Nuclear waste governance in the Netherlands' in Brunnengraber et al., op. cit. Chapter in V, pp. 281-298.

Auffermann, B., Suomela, P., Kaivo-Oja, J. Vehmas, J. and Lukkanen, J. 'A final solution for a big challenge. The governance of nuclear waste disposal in Finland, in Brunnenghraber et al. op. cit. Chapter in IV, pp. 227-248

Blowers, A., 2017. The Legacy of Nuclear Power Earthscan

Brunnengraber, A., di Nucci, M.R., Loada, A.M.I., Mex, L. and Schreurs, M. (eds.), 2015. Nuclear Waste Management: an International Comparison Springer

Chilvers, J and Burgess, J., 2008. 'Power relations: the politics of risk and procedure in nuclear waste governance' Environment and Planning A: economy and space 40:8, 1881-1900.

Cochran, T., Feiveson, H., Patterson, W., Pshakin, G., Ramana, M., Schneider, M., Suzuki, T. and von Hippel, F., 2010. Fast Breeder Reactor Programs: history and status. A research report on International Panel on Fissile Materials, (February 2010)

CoRWM (Committee on Radioactive Waste Managment ), 2006. Managing our Radioactive Waste Safely, CoRWM's Recommendations to Government (July 2006). 
Defra, BERR and the devolved administrations for Wales and Northern Ireland, 2008. Managing Radioactive Waste Safely: a framework for implementing geological disposal, Cm 7836, (1 June 2008).

DTI (Department of Trade and Industry), 2003. Our energy future - creating a low carbon economy Cm 5761, February.

Gibb, F., Travis, K.P., McTaggart, N.A., Burley, D. and Hesketh, K.W., 2008. 'Modeling temperature distribution around very deep borehole disposals of HLW' Nuclear Technology 163: 62-73

Gowing, M., 1974. Independence and Deterrence: Britain and Atomic Energy 1945-52 (Volume 1) Macmillan.

HMG (Her Majesty's Government), 2017. The Clean Growth Strategy - leading the way to a low carbon future (October 2017).

Hocke, P. and Kallenbach-Herbert, B., 2015. 'Always the same old story? Nuclear Waste Governance in Germany in Brunnengraber et al., op. cit. Chapter in Part IV, pp. 177-202.

Macfarlane, A. and Ewing, R. (eds.), 2006. Uncertainty Underground: Yucca mountain and the Nation's High-Level Nuclear Waste MIT.

MacKerron, G., 2015. 'Multiple Challenges: Nuclear Waste Governance in the United Kingdom' in Brunnengraber et al. op. cit. Chapter in III, pp. 101-117.

NWMO (Nuclear Waste Management Organisation), 2018. Implementing Adaptive Phased Management (March 2018).

OECD/NEA, 2013. The Economics of the Back End of the Nuclear Fuel Cycle NEA no. 7061

Royal Commission on Environmental Pollution, 1976. Nuclear Power and the Environment 6th Report, Cm 6618.

Schneider, M. and Marignac, Y., 2008. Spent Fuel Reprocessing in France International Panel on Fissile Materials Research Report 4, 8 (May 2008).

Swahn, J. and Kaberger, T., 2015. Governance and management of radioactive waste in Sweden in Brunnengraber et al. (op. cit.) Chapter in IV pp. 203-225.

World Nuclear News, 2017. 'Further delay to completion of Rokkasho facilities' (December 28. 2017).

Von Hippel, F and MacKerron, G., 2015. Alternatives to MOX International Panel on Fissile Materials Research Report no. 13 (April 2015).

Open Access This chapter is licensed under the terms of the Creative Commons Attribution 4.0 International License (http://creativecommons.org/licenses/by/4.0/), which permits use, sharing, adaptation, distribution and reproduction in any medium or format, as long as you give appropriate credit to the original author(s) and the source, provide a link to the Creative Commons license and indicate if changes were made.

The images or other third party material in this chapter are included in the chapter's Creative Commons license, unless indicated otherwise in a credit line to the material. If material is not included in the chapter's Creative Commons license and your intended use is not permitted by statutory regulation or exceeds the permitted use, you will need to obtain permission directly from the copyright holder.

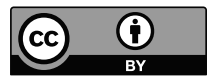

